\title{
Fusão internacional no mercado de serviços oftálmicos e óticos
}

\author{
Conselho Administrativo de Defesa Econômica (Cade)
}

\section{Ato de Concentração no 08700.004446/2017-84}

Requerentes: Essilor International (Compagnie Générale d'Optique) S.A. e Luxottica Group S.p.A.

Advogados: Barbara Rosenberg, Joana Cianfarani e outros.

Terceiros Interessados: Carl Zeiss Vision Brasil Indústria Óptica Ltda. e Fotoptica Ltda.

Advogados: André Marques Gilberto, Eduardo Caminati Anders e outros. Conselheiro-Relator: Paulo Burnier da Silveira

\section{Voto}

\section{Versão de acesso público}

Ementa: Ato de Concentração. Fusão internacional. Essilor International e Luxottica Group. Mercados de substratos oftálmicos, máquinas oftálmicas, laboratórios óticos, instrumentos optométricos, armações para óculos e varejo de produtos e serviços óticos. Aprovação sem restrições pela SG. Recurso de Terceiro Interessado. Ausência de problemas concorrenciais. Recurso conhecido e, no mérito, improvido. 


\section{Relatório}

1. Trata-se de recurso voluntário interposto pela Terceira Interessada Carl Zeiss Vision Brasil Indústria Óptica Ltda. (SEI no 0452714) em 12.03.2018 contra Despacho da Superintendência Geral do CADE (SG/Cade) no 230/ 2018 (SEI nº 0444536), que decidiu pela aprovação sem restrições do Ato de Concentração n⿳0 08700.004446/2017-84.

2. A notificação do Ato de Concentração ocorreu em 18.07.2017 e, por meio do Despacho SG no 1047/2017, foi determinada emenda, a qual foi apresentada ao CADE em 06.09.2017. Em 12/09/2017, o Edital nº 287/2017 (SEI nº 0385381) deu publicidade à Operação em análise.

3. Em 29.09.2017, por meio do Despacho SG no 1442/2017 (SEI n⿳o 0392466), a SG deferiu o pedido de intervenção como Terceira Interessada da Carl Zeiss Vision Brasil Indústria Óptica Ltda. no processo.

4. Em 22.02.2017, terminada a fase instrutória, a SG/Cade elaborou o Parecer 2/2018/CGAA2/SGA1/SG/CADE (SEI no 0445156), que recomendou a aprovação da Operação sem restrições.

5. Em 22.02.2018, referido parecer foi acolhido pelo Despacho da Superintendência Geral do CADE (SG/Cade) nº 230/2018 (SEI nº 0444536).

6. Em 12.03.2018, irresignada, a Terceira Interessada Carl Zeiss Vision Brasil Indústria Óptica Ltda. interpôs Recurso Voluntário (SEI no 0452714).

7. Em 14.03.2018, nos termos da Certidão (SEI no 0453712), o processo em epígrafe foi distribuído ao meu gabinete, conforme o sorteio realizado na 165 - Sessão Ordinária de Distribuição.

8. Em 20.03.2018, por meio do Despacho Decisório nº 2/2018/GAB5/CADE (SEI no 0456184), o Conselheiro-Relator conheceu do recurso e determinou a inclusão em pauta para julgamento na próxima Sessão Ordinária de Julgamento do Tribunal Administrativo de Defesa Econômica, nos termos do art. 170, I e $\$ 1^{\circ}$, do RICade:

Art. 170. Em até 5 (cinco) dias úteis a partir do recebimento do recurso contra a decisão de aprovação do ato de concentração pela Superintendência-Geral, o Conselheiro-Relator:

I. conhecerá do recurso e determinará a sua inclusão em pauta para julgamento; (grifos do voto) 
II. conhecerá do recurso e determinará a realização de instrução complementar, podendo, a seu critério, solicitar que a Superintendência-Geral a realize, declarando os pontos controversos e especificando as diligências a serem produzidas; ou

III. não conhecerá do recurso, determinando o seu arquivamento.

9. Referido Despacho determinou ainda a abertura de prazo de cinco dias úteis para que as Recorridas, querendo, apresentassem manifestação sobre o recurso, nos termos do art. $65, \S^{2}{ }^{\circ}$, da Lei $n^{\circ} 12.529 / 11$ e do art. $170, \S 1^{\circ}$, do RICade, acima transcrito.

10. Em 23.03.2018, as Requerentes apresentaram manifestação sobre o recurso, reiterando os fundamentos de aprovação sem restrições do Ato de Concentração (SEI no 0458186 ).

\section{Operação}

11. A operação consiste na fusão internacional das atividades da Essilor International (Essilor) S.A. e da Luxottica Group S.A (Luxottica).

12. A Essilor tem sede na França e atua em todas as fases do desenvolvimento de substratos e lentes oftálmicas, do design e da fabricação até a venda no comércio atacadista. A empresa possui 2 (duas) fábricas localizadas no Brasil, uma em Manaus/AM e outra em Tupã/SP. O grupo possui ainda 26 (vinte e seis) laboratórios óticos e 6 (seis) instalações para tratamento de lentes no país. Suas principais marcas são Varilux, Crizal, Transitions, Kodak, Eyezen e Xperio. A Essilor também fabrica e comercializa máquinas oftálmicas de surfaçagem, tratamento e montagem, instrumentos optométricos e outros produtos e serviços relacionados. O grupo ainda produz cativamente armações de óculos de grau que são vendidas em seus serviços de varejo online de óculos de grau e de sol e de lentes de contato (o que inclui os sites eÓtica, e-Lens e Glasses4You).

13. A Luxottica tem sede na Itália e atua no design, fabricação e distribuição de armações para óculos de grau e de óculos de sol. O grupo possui 12 fábricas no mundo, inclusive uma no Brasil em Campinas/SP. Seu portfólio de marcas inclui Ray-Ban, Oakley, Vogue, Eyewear, Persol, Oliver Peoples e Alain Mikli, além de marcas licenciadas como Giorgio Armani, Burberry, Bulgari, Chanel, Coach, Dolce \& Gabbana, Michael Kors, Prada, Ralph Lauren, Tiffany \& Co., Valentino e Versace. No Brasil, o grupo ainda 
inclui varejo físico e online de óculos de sol e de grau pelas lojas Sunglass Hut (lojas físicas e online), Oakley (lojas físicas e online), Óticas Carol (apenas lojas físicas) e Ray-Ban (apenas lojas online). A Luxottica fornece lentes cativamente às Óticas Carol por meio do laboratório Global Lux Ltda., além de lentes com características esportivas fabricadas em Foothill Ranch, na Califórnia (EUA), para revendedores da Oakley em todo o mundo, inclusive no Brasil.

14. A Operação, tal qual definido pela SG em sua Nota Técnica (SEI nº 0444536), afeta os seguintes mercados relevantes, todos eles definidos na dimensão geográfica nacional:

i. Fabricação e distribuição de substratos oftálmicos

ii. Máquinas oftálmicas: máquinas de surfaçagem, de tratamento e de montagem

iii. Laboratórios óticos: fornecimento de lentes acabadas ao varejo ótico

iv. Instrumentos optométricos

v. Armações para óculos de sol e de grau

vi. Varejo de produtos e serviços óticos

15. Em linhas gerais, a Operação consiste na fusão de agentes que ocupam posições complementares na cadeia de fabricação, montagem e revenda de produtos e serviços óticos. A SG analisou apenas uma única sobreposição horizontal derivada da Operação, concernente ao mercado de varejo de produtos e serviços óticos físico e online. ${ }^{1}$ Desse modo, as principais preocupações concorrenciais discutidas na presente Operação estão relacionadas aos seus efeitos não horizontais, notadamente à formação ou ao reforço de integrações verticais e ao fortalecimento do poder de portfólio das Requerentes.

16. A figura abaixo ilustra as relações estabelecidas entre as Requerentes nos mercados afetados pela Operação:

1 Não foram analisadas as sobreposições horizontais no mercado de lentes vendidas para laboratórios óticos e no mercado de fornecimento de óculos de sol e de armações para óculos de grau porque, em ambos os casos, uma das Requerentes atua no mercado apenas cativamente. 


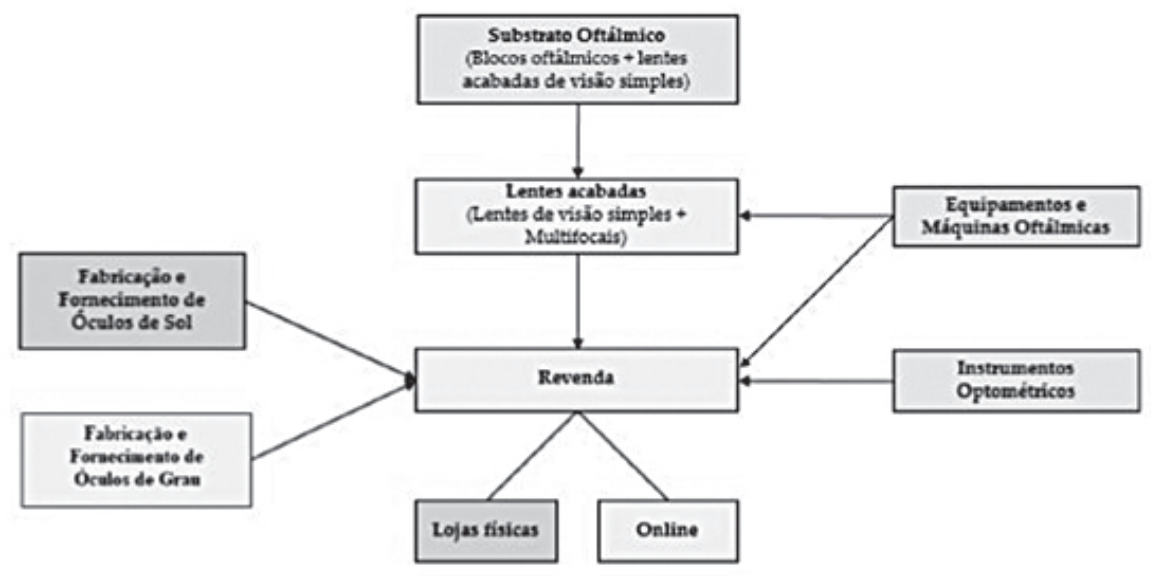

\begin{tabular}{|l|l|}
\hline \multicolumn{2}{|c|}{ Legenda } \\
\hline & Apenas Essilor \\
\hline & Apenas Luxottica/OC 17 \\
\hline & Essilor e Luxottica/OC \\
\hline
\end{tabular}

Fonte: Nota Técnica da SG (SEI no 0445148$)^{2}$

\section{Mérito}

17. Antes de adentrar ao mérito do Recurso Voluntário em tela, destaca-se que o juízo de cognição desta decisão está adstrito ao exame das razões recursais apresentadas pela Terceira Interessada, de modo que não serão investigados aspectos da análise concorrencial do Ato de Concentração que não foram objeto de impugnação por parte da Recorrente.

18. Essa restrição decorre da própria formatação jurídica do instituto do Recurso Voluntário previsto no art. 65, inciso I, da Lei no $12.529 / 11$ e no art. 170 do RICade.

19. Considerando que a Lei $n^{0} 12.529 / 11$ prevê duas hipóteses de apreciação de atos de concentração sumários por parte do Tribunal Administrativo do

2 A versão colorida desta figura pode ser verificada no site do Cade: $<$ https://bit.ly/2M3eXiB $>$. Acesso em: 11 jan. 2019. 
CADE - uma no caso de avocação (art. 65, inciso II, da Lei nº 12.529/11) e outra no caso de interposição de recurso voluntário (art. 65, inciso I, da Lei n⿳0 12.529/11) - é possível inferir que os dois caminhos geram repercussões diferentes. Enquanto a avocação devolve ao colegiado a análise em profundidade da Operação (eventualmente circunscrita à fundamentação do despacho de avocação), o Recurso Voluntário tem finalidade diversa, voltada à impugnação específica dos fundamentos da decisão recorrida.

20. Abaixo segue o dispositivo regimental do RICade que estabelece a possibilidade e contornos de eventual recurso interposto contra a decisão de aprovação de Ato de Concentração:

Art. 162. No prazo de 15 (quinze) dias contados a partir da publicação da decisão da Superintendência-Geral que aprovar o ato de concentração:

$\S 1^{\circ}$ Do recurso contra a decisão de aprovação do ato de concentração pela Superintendência-Geral, deverão constar os motivos pelos quais o ato aprovado poderá implicar eliminação da concorrência em parte substancial de mercado relevante, reforço de posição dominante ou dominação de mercado relevante de bens e serviços, e todos os documentos e pareceres indispensáveis à análise dos fatos alegados. (frisos do voto)

21. Reconhecendo essa finalidade específica, a jurisprudência recente do CADE tem majoritariamente considerado que, para serem cabíveis, os Recursos Voluntários devem apresentar ao Tribunal fatos ou argumentos que ainda não tenham sido apreciados pela instância $a$ quo.

22. A esse respeito, verifica-se que, desde a edição da Lei $n^{0}$ 12.529/2011, o Tribunal do CADE julgou 6 (seis) recursos em atos de concentração, sendo que em 4 (quatro) deles os recursos foram arquivados por meio de despacho decisório, nos termos do art.170, inciso III, do RICade. Em todos esses casos, considerou-se que os recursos seriam inadmissíveis justamente por não trazerem argumentos novos em relação à análise da SG. Em apenas 2 (dois) precedentes, considerou-se que o recurso merecia ser conhecido em particular, cita-se o precedente mais recente do CADE, de 22.12.2017, da Conselheira Polyanna Vilanova, cujo despacho de conhecimento foi fundamentado no preenchimento de requisitos extrínsecos e intrínsecos de admissibilidade (SEI no 0423443). 
23. Esse levantamento atesta que o Tribunal tem sido bastante cauteloso ao analisar a admissibilidade de Recursos Voluntários, principalmente porque o recebimento desses recursos pode obstar a consumação de Operações acerca das quais o CADE, por intermédio da SG, já realizou um juízo positivo de escrutínio concorrencial.

24. Conforme será analisado, o Recurso Voluntário em apreço visa desconstituir os fundamentos da decisão de aprovação sem restrições do Ato de Concentração por parte da SG. Em linhas gerais, a Recorrente sustenta que essa aprovação resultaria "em uma substancial concentração e integração em virtualmente todos os setores da cadeia de valor de proteção da saúde visual, gerando sérias preocupações concorrenciais" (SEI $n^{0}$ 0452714). Afirma-se ainda que, diante das sérias preocupações concorrenciais identificadas pela própria SG, os fundamentos da decisão recorrida "soam como especulações - com toda licença, quase como um exercício de 'wishfull thinking' - e devem ser reformadas por este E. Tribunal" (SEI no 0452714).

25. Além de fazer impugnações gerais em relação à decisão recorrida, a peça recursal estruturou quatro argumentos que supostamente seriam suficientes para a reforma da decisão da SG. Esses argumentos serão analisados nos itens abaixo, sendo que dois deles serão examinados conjuntamente por estarem inter-relacionados (ampliação do poder de portfólio das Requerentes e incentivos para adoção de práticas exclusionárias e discriminatórias).

\subsection{Alegações da Recorrente}

\subsubsection{Reforço de posição dominante em mercados verticalmente integrados}

26. O primeiro argumento da Recorrente consiste na tese de que a Operação geraria não apenas um reforço da posição dominante das Requerentes nos mercados verticalmente integrados da cadeia de valor de produtos e serviços óticos, mas implicaria prejuízo da concorrência em mercados já bastante concentrados, in verbis: 
Em primeiro lugar, a Operação não gera "apenas um reforço" nas estruturas extremamente verticalizadas das Requerentes. Pelo contrário: a Operação representa a combinação total dos negócios das duas líderes da indústria ótica no Brasil, que possuem posição dominante em vários mercados verticalmente integrados e já altamente concentrados (SEI n⿳o 0452714, com grifos do original)

27. Do ponto de vista concorrencial, a Recorrente sustenta que, com a consumação da Operação, as Requerentes passariam a controlar ou a influenciar todos os pontos de acesso à indústria brasileira para a fabricação e distribuição de produtos óticos aos consumidores finais, de modo que a Operação geraria incentivos para que as Requerentes dificultassem o acesso de concorrentes ao mercado em um cenário pós-Operação. Defende-se também que o fechamento de mercado seria provável pelo fato de as Requerentes controlarem diversos níveis da cadeia de distribuição e deterem as principais marcas de armações, que são consideradas pelos consumidores marcas "must have".

28. De plano, verifica-se que as alegações são feitas de forma genérica, sem qualquer fato ou documento novo capaz de sustentar tais alegações. A Recorrente defende, de forma ampla, que o controle de pontos-chaves da cadeia de valor por parte das Requerentes seria capaz de gerar efeitos anticompetitivos derivados de integrações verticais.

29. Conforme assentado na jurisprudência deste Tribunal, ${ }^{3}$ a análise de integrações verticais é relevante para o controle de estruturas especialmente porque fusões verticais podem ensejar (i) aumento de coordenação entre concorrentes ou ainda (ii) incentivos de fechamento de mercado a montante ou a jusante.

30. A avaliação dos impactos anticompetitivos de fusões verticais é desafiadora justamente porque as integrações verticais, em si, geram repercussões que implicam vetores opostos na análise de estruturas. Por um lado, a atuação simultânea em mais de um elo da cadeia tende a propiciar a internalização de marginalização dupla da firma integrada. De outro, o controle de níveis subsequentes da cadeia gera, ao menos em tese, a possibilidade de fechamento de mercado ou o aumento do custo de rivais.

3 Ver, por exemplo: Ato de Concentração 08012.005212/2009-01 (Satipel Industrial / Duratex). Voto-Relator do ex-Conselheiro Carlos Emmanuel Joppert Ragazzo. 
31. Pelo fato de esses dois efeitos serem gerados por uma mesma fonte, a avaliação dos possíveis impactos anticompetitivos requer o emprego de metodologias adequadas para se medir os efeitos da Operação. Conforme previsto no Vertical Mergers da Organização para a Cooperação e Desenvolvimento Econômico (OCDE), a avaliação da possibilidade de fechamento de mercado envolve o exame de pelo menos três aspectos relacionados à Operação (i) a capacidade de as firmas fusionadas gerarem fechamento de mercado; (ii) os incentivos de as firmas integradas gerarem fechamentos de mercado e ainda (iii) os possíveis efeitos do fechamento nos mercados afetados. ${ }^{4}$

32. Essa digressão se faz necessária no caso em tela para que seja depurada a argumentação da Recorrente de que a aprovação do Ato de Concentração geraria efeitos anticompetitivos pelo simples fato de a Operação representar “a combinação total dos negócios das duas líderes da indústria ótica no Brasil, que possuem posição dominante em vários mercados verticalmente integrados e já altamente concentrados" (SEI no 0452714). Na realidade, a simples atuação conjunta das Requerentes nos mercados verticalmente integrados, por si só, não implica a confirmação de que Essilor/Luxottica teriam condições e incentivos de realizar fechamentos de mercado upstream ou downstream.

33. Ainda que não exista no Brasil um Guia de Fusões não Horizontais, tal qual ocorre na União Europeia e nos Estados Unidos, o CADE tem diferido a avaliação de integrações verticais no controle de estruturas em um juízo de probabilidade e em um juízo de possibilidade de fechamento de mercado. Assim como ocorre na análise de fusões horizontais, o juízo de possibilidade se faz prejudicial em relação ao juízo de probabilidade.

34. No caso em tela, a SG identificou a formação de 5 (cinco) integrações verticais geradas, ou pelo menos reforçadas, pela Operação:

i. Integração vertical entre os mercados de substratos oftálmicos (Essilor) e o mercado de lentes vendidas por laboratórios óticos (em que Luxottica tem atuação cativa);

4 Do original: "The analytical framework for assessing the likelihood of anticompetitive foreclosure (input or customer) involves an evaluation of (i) the integrating firm's ability to foreclose, (ii) the integrating firm's incentives to foreclose, and (iii) the effect of foreclosure on the downstream market". (Organização para a Cooperação e Desenvolvimento Econômico (OCDE). Policy Roundtables. Vertical Mergers. 2007). 
ii. Integrações verticais entre os mercados de máquinas de surfaçagem, de máquinas de tratamento e de máquinas de montagem comercial (Essilor) e os mercados de lentes vendidas por laboratórios óticos (em que Luxottica tem atuação cativa) e de varejo físico e online de produtos e serviços óticos (Luxottica);

iii. Integração vertical entre o mercado de instrumentos optométricos (Essilor) e o mercado de varejo físico e online de produtos e serviços óticos (Luxottica);

iv. Integração vertical entre o mercado de fornecimento de óculos de sol e de armações para óculos de grau (Luxottica) e o mercado de varejo físico e online de produtos e serviços óticos (Essilor, no varejo online);

v. Integração vertical entre o mercado de lentes vendidas por laboratórios óticos (Essilor) e o mercado de varejo físico e online de produtos e serviços óticos (Luxottica).

35. Ao término da instrução, a SG diagnosticou que nenhuma das integrações verticais derivadas da Operação geraria efetiva probabilidade de fechamento de mercado downstream ou upstream, ainda que, em algumas delas, pudesse se falar, em tese, em possibilidade de fechamento de mercado.

36. No que atine às integrações verticais entre substratos e máquinas da Essilor e lentes vendidas por laboratórios óticos e varejo físico e online da Luxottica, a análise desenvolvida pela SG concluiu que não haveria qualquer risco de fechamento de mercado downstream no varejo físico e online de produtos e serviços óticos, considerando a baixa participação de mercado da Luxottica nos mercados integrados (no máximo [ACESSO RESTRITO À LUXOTTICA] em lentes acabadas e [ACESSO RESTRITO À LUXOTTICA] em varejo físico e online).

37. No que diz respeito à possibilidade de fechamento do mercado downstream de lentes fornecidas por laboratórios óticos, verificou-se que a integração vertical já seria prévia à Operação por parte da Essilor e que a integração da Luxottica geraria um reforço baixíssimo dessa integração, considerando que essa empresa possui apenas um único laboratório ótico (Global Lux) voltado a fornecer lentes apenas para o varejo das Óticas Carol, nem mesmo conseguindo atingir toda a rede.

38. Em relação aos riscos de fechamento de mercado upstream no mercado de substratos oftálmicos, isto é, aos riscos de que a estrutura final restringisse o acesso de concorrentes (laboratórios óticos e varejistas) a máquinas e 
substratos oftálmicos, a instrução mostrou que tais riscos, embora sejam possíveis, não são prováveis. Isso porque atualmente a Essilor já possui uma estrutura integrada nessas cadeias, uma vez que atua, de forma simultânea, na fabricação de substratos oftálmicos, na fabricação de lentes acabadas e na revenda. Já a Luxottica, que também atua de forma cativa no mercado de fabricação de lentes acabadas, possui um único laboratório ótico voltado ao atendimento cativo de parte de sua rede.

39. Nesse cenário, é improvável que o modelo de atuação da Luxottica passasse a ser implementado pelas Requerentes em um cenário pós-operação. Como bem observado pela SG, "como o único laboratório da Luxottica tem atuação cativa e bastante reduzida, suas possibilidades de crescimento dependem do crescimento das redes varejistas a que eles estão associados, o que diminui o incentivo para a adoção de práticas exclusionárias" (SEI $n^{\circ}$ 0444536). Assim, "eventuais perdas financeiras decorrentes da recusa ou discriminação na venda para outros laboratórios dificilmente seriam compensadas pelo aumento das vendas do único laboratório das Óticas Carol" (SEI no 0444536).

40. O mesmo raciocínio se aplica à integração entre máquinas oftálmicas e laboratórios óticos. Considerando que hoje a Essilor também já atua de forma integrada nesses dois segmentos e que a empresa adota um modelo de mercado aberto, a Operação representaria um reforço pouquíssimo significativo dessa integração vertical prévia à operação, já que a Luxottica possui apenas um único laboratório ótico que seria integrado à estrutura da Essilor.

41. Também não é possível esperar retornos significativos no caso de práticas exclusionárias resultantes da integração entre máquinas de montagem comercial, de um lado, e varejistas físicos e online, de outro. Isso porque a instrução demonstrou que tais máquinas não são comuns nem essenciais para a atividade das óticas, que, em geral, mandam as armações para os laboratórios óticos, que fazem a montagem das lentes. Desse modo, eventual restrição no acesso desse tipo de maquinário imposto pela Essilor não teria impactos significativos sobre o varejo ótico.

42. No tocante à integração vertical entre os mercados de instrumentos optométricos da Essilor e os mercados de varejo físico e online de produtos e serviços óticos da Luxottica, verificou-se que não haveria possibilidade de fechamento de mercado downstream, já que Luxottica e Essilor não são players relevantes nacionalmente em revenda. Conforme ilustrado na Tabela 1 abaixo, a estrutura de oferta do mercado de varejo físico e online de 
produtos e serviços óticos, por faturamento, é extremamente pulverizada no Brasil. A Óticas Carol, que é o maior grupo de varejo nacional, detém apenas 5,52\% de market share, o que indica a elevada rivalidade nesse segmento:

Tabela 1

Estrutura de oferta do cenário de mercado de varejo físico e online de produtos e serviços óticos no Brasil em 2016, por faturamento

\section{[ACESSO RESTRITO ÀS REQUERENTES]}

43. Desse modo, verificou-se que não seria possível que a estrutura final das Requerentes restringisse o acesso de fabricantes concorrentes de instrumentos otpométricos aos canais de distribuição em questão (varejistas físicos e online).

44. Já que no que se refere aos riscos de fechamento de mercado upstream, verificou-se que esses riscos, embora fossem possíveis, não seriam prováveis, já que hoje a maior parte do faturamento da Luxottica com o varejo de produtos e serviços óticos ([ACESSO RESTRITO À LUXOTTICA] do faturamento do grupo) advém do pagamento de royalties por parte de franquiadas das Óticas Carol. Assim, não seria possível que um retorno auferido no varejo compensasse adequadamente eventuais perdas em que a Essilor pode incorrer para a adoção de práticas exclusionárias envolvendo instrumentos optométricos.

45. Em relação à integração vertical entre óculos de sol e armações para óculos de grau da Luxottica e varejo online da Essilor, verificou-se que o fechamento de mercado downstream sequer seria possível, dada a baixa participação da Luxottica no mercado de varejo físico e online (inferior a [ACESSO RESTRITO À LUXOTTICA]). No tocante aos riscos de fechamento de mercado upstream, embora esses fossem possíveis diante da detenção de marcas essenciais de armações por parte da Luxottica, a instrução mostrou que não haveria probabilidade de fechamento de mercado.

46. Conforme apurado na instrução, a participação da Essilor no varejo é bastante lateral (conforme visto na Tabela 1 acima). Por esse motivo, a SG considerou adequadamente que "a integração da Luxottica com o varejo online da Essilor não resulta em uma alteração significativa no varejo já praticado pela Luxottica, semelhantemente ao que ocorre quanto à 
integração dos laboratórios da Luxottica ao fornecimento de máquinas e substratos oftálmicos pela Essilor".

47. Por fim, no que concerne à integração vertical entre lentes vendidas por laboratórios óticos da Essilor e o varejo físico e online de produtos e serviços óticos da Luxottica, também não haveria possibilidade de fechamento de mercado downstream, já que nem a Luxottica muito menos a Essilor são players relevantes nacionalmente no varejo físico e online de produtos e serviços óticos.

48. Quanto aos riscos de fechamento de mercado upstream, tal situação não seria provável, uma vez que a dinâmica do mercado varejista é baseada na aquisição, por parte das óticas, de lentes de mais de um laboratório. Conforme apurou a SG, os varejistas entendem que esse multisourcing é um benefício ao negócio, de sorte que, se fossem adotadas estratégias de fechamento de mercado, outros laboratórios óticos estariam prontos para atender óticas concorrentes.

49. Também se considerou que a discriminação de clientes, com a concessão de descontos diferenciados para varejistas, seria pouco provável, já que, em razão da estrutura pulverizada do mercado, não seria esperado que o retorno auferido no varejo compensasse adequadamente eventuais perdas que a Essilor poderia ter com a adoção de práticas exclusionárias no fornecimento de lentes acabadas.

50. Por todos esses motivos, a tese recursal de que a Operação resultaria em um fechamento dos pontos de acesso da indústria brasileira para a fabricação e distribuição de produtos óticos não prospera. Mesmo que as Requerentes passem a controlar diversos níveis da cadeia de produção, o perfil de atuação de Essilor e da Luxottica indica uma clara complementaridade que não gera incentivos de fechamento de mercado: a integração da Luxottica agrega pouquíssimo aumento da participação da Essilor nos mercados superiores da cadeia, ao passo que a participação desta empresa no varejo agrega pouquíssimo aumento da participação da Luxottica no nível de revenda.

\subsubsection{Ampliação do poder de portfólio e incentivos para práticas discriminatórias}

51. Um segundo argumento trazido pela Recorrente está relacionado aos efeitos de portfólio gerados pela Operação. Nesse sentido, defende-se que, in verbis: 
Em segundo lugar, o fato de Essilor e da Luxottica já operarem de maneira extremamente verticalizada, adotando posturas comerciais bastante agressivas nos respectivos mercados, na verdade reforça (ao invés de afastar) as preocupações concorrenciais que a combinação de seus negócios pode gerar no mercado de produtos e serviços óticos no Brasil. (SEI no 0452714 , com grifos do original)

52. A ampliação do poder de portfólio, na visão das Requerentes, faria com que nenhum outro player pudesse competir com as Requerentes em um cenário pós-operação, criando uma verdadeira "ilha de escolha" ao consumidor final. Ainda de forma relacionada a esse segundo argumento, a Recorrente defende que seria especulativa a conclusão da SG de que não haveria incentivos por parte da Essilor/Luxottica na adoção de práticas exclusionárias e discriminatórias no mercado de produtos e serviços óticos. Nesse sentido, sustenta-se que, in verbis:

Em terceiro lugar, o argumento de que "não haveriam incentivos" para Essilor/Luxottica adotarem práticas exclusionárias e discriminatórias no mercado de produtos óticos soa especulativo e completamente destoante das informações levantadas ao longo da instrução probatória. (SEI n⿳o 0452714, com grifos do original)

53. Ainda de acordo com a Recorrente, essas práticas exclusionárias e discriminatórias poderiam restar consubstanciadas, sobretudo, "na implementação de condições comerciais que estimulem a compra conjunta dos produtos de ambas as empresas" ou ainda na capacidade das Requerentes de "constantemente aumentar o nível de 'desconto' oferecido na venda de equipamentos".

54. Conforme esclarecido na Nota Técnica da SG, a Operação de fato tem o condão de gerar um único agente econômico capaz de fornecer todos os produtos que varejistas de produtos e de serviços óticos precisam adquirir, tais como lentes oftálmicas, óculos de sol e armações para óculos de grau e, em uma importância menor, instrumentos optométricos. Desse modo, a aprovação do AC geraria um player cujo portfólio total não seria compatível com o de nenhum outro existente no mercado.

55. A combinação de produtos e marcas é resultado típico das chamadas fusões conglomeradas, isto é, fusões que se consumam entre empresas que são ativas em mercados intimamente relacionados, como, por exemplo, 
em mercados que envolvem produtos complementares ao longo de uma cadeia produtiva ou em mercados que pertencem a um mesmo tipo de produto. $^{5}$

56. O Guia de Fusões Não Horizontais da União Europeia define que a principal preocupação das autoridades de concorrência na avaliação de efeitos conglomerados, decorrentes de poder de portfólio, está relacionada à existência de riscos de fechamento de mercado, principalmente por meio da adoção de estratégias de tying e bundling. Nesse sentido, transcreve-se o seguinte trecho: ${ }^{6}$

The main concern in the context of conglomerate mergers is that of foreclosure. The combination of products in related markets may confer on the merged entity the ability and incentive to leverage a strong market position from one market to another by means of tying or bundling or other exclusionary practices. Tying and bundling as such are common practices that often have no anticompetitive consequences. Companies engage in tying and bundling in order to provide their customers with better products or offerings in costeffective ways. Nevertheless, in certain circumstances, these practices may lead to a reduction in actual or potential rivals' ability or incentive to compete. This may reduce the competitive pressure on the merged entity allowing it to increase prices.

57. Ainda de acordo com o referido Guia, no âmbito do controle de estruturas, caso prováveis, os riscos de fechamento de mercado, principalmente por meio da adoção de estratégias de tying e bundling, devem ser ponderados com outros eventuais efeitos positivos da Operação, como o aumento de poder compensatório dos compradores, a possibilidade de novas entradas e a produção de eficiências.

5 De acordo com o Guia de Concentrações Não Horizontais da União Europeia: “Conglomerate mergers are mergers between firms that are in a relationship which is neither horizontal (as competitors in the same relevant market) nor vertical (as suppliers or customers). In practice, the focus of the present guidelines is on mergers between companies that are active in closely related markets (e.g. mergers involving suppliers of complementary products or products that belong to the same product range)". Comissão Europeia. "Guidelines on the assessment of non-horizontal mergers under the Council Regulation on the control of concentrations between undertakings". Bruxelas, 2008.

6 Comissão Europeia. "Guidelines on the assessment of non-horizontal mergers under the Council Regulation on the control of concentrations between undertakings". Bruxelas, 2008. 
58. Desse modo, ainda que as estratégias como o tying e o bundling não sejam anticompetitivas em absoluto, é possível que elas provoquem uma redução da capacidade de atuação dos rivais, sobretudo quando uma das Requerentes já detém poder de mercado em determinado segmento da cadeia e apresenta incentivos de alavancar sua posição dominante em outro elo.

59. Destaca-se que, na jurisprudência recente do CADE, este Tribunal analisou pelo menos 2 (dois) atos de concentração em que a discussão sobre efeitos conglomerados decorrentes do reforço do poder de portfólio das Requerentes foi colocada como um elemento importante de análise do controle de estruturas.

60. Nesse sentido, no âmbito do AC no 08700.001097/2017-49 (Bayer Aktiengesselschaft e Monsanto Company), considerou-se que a Operação geraria efeitos conglomerados consideráveis, uma vez que as Requerentes atuavam simultaneamente nos níveis de produção e comercialização de biotecnologia, sementes e defensivos agrícolas, principalmente nas culturas de soja e algodão. Na oportunidade, foram impostos remédios comportamentais de proibição de venda casada e de proibição de empacotamentos de produtos (bundling) com efeitos anticompetitivos perante os canais de distribuição de sementes e defensivos agrícolas.

61. Já no julgamento do AC nº 08700.008483/2016-81 (WEG Equipamentos Elétricos S.A. e TGM Indústria e Comércio de Turbinas e Transmissões Ltda.), também se entendeu que a Operação resultaria em vantagem competitiva do portfólio WEG/TGM, em decorrência da possibilidade de fornecimento de solução integrada de turbogerador. A fim de endereçar essa sensibilidade concorrencial, também foi imposto remédio comportamental, determinando-se que a WEG se comprometeria a assegurar aos seus clientes, atuais, potenciais e futuros, a possibilidade de comprar os equipamentos que integram os turbogeradores (especificamente, turbinas a vapor, redutores turbo e geradores para turbinas a vapor) de forma integrada ou avulsa no Brasil.

62. O caso em tela, porém, parece ser bastante distinto desses dois anteriores. Diferente desses precedentes, em que a análise desenvolvida pela SG e pelo Tribunal indicou uma efetiva probabilidade de fechamento de mercado decorrente de efeitos conglomerados, no caso em apreço, a Nota Técnica da SG concluiu, após detalhada instrução, que não havia evidências significativas de possibilidade de imposição de poder de portfólio por parte das Requerentes. 
63. Apenas para não deixar qualquer dúvida quanto a esse ponto, é válido destacar que a preocupação com o risco de adoção de práticas exclusionárias ou de práticas de concessão de condições favorecidas decorrente do aumento do poder de portfólio foi um dos motivos que levou a SG a declarar a complexidade do AC em exame. Essas práticas, em teoria, poderiam ser levadas a cabo tanto nos níveis superiores de cadeia (no fornecimento de substratos oftálmicos e de máquinas oftálmicas) quanto nos níveis inferiores (de fornecimento de lentes acabadas e de armações para o varejo).

64. O aprofundamento da instrução, no entanto, mostrou que a concessão de supostos descontos condicionados entre máquinas e substratos oftálmicos nos níveis superiores da cadeia não envolvia evidências de tratamento discriminatório.

65. Ressalta-se, a propósito, que a preocupação com concessão de descontos por parte da Essilor no mercado de máquinas oftálmicas já havia sido anteriormente enfrentada pelo CADE na análise do AC nº 08012.010967/201133 (Satisloh / CM). Nesse caso, já se antevia a possibilidade de a Essilor (que controlava a Satisloh) favorecer laboratórios que integravam o programa Essilor Alliance ou por meio do favorecimento de laboratórios não vinculados ao programa, mas que poderiam pactuar exclusividade na compra de blocos oftálmicos com o grupo Essilor.

66. Nesse precedente, o Tribunal do CADE, seguindo voto de relatoria do exConselheiro Eduardo Pontual Ribeiro, condicionou a aprovação do AC à celebração de Termo de Compromisso de Desempenho (TCD), por meio do qual as Requerentes se comprometiam a não ofertar pacotes de produtos (bundled products) no fornecimento de blocos e lentes oftálmicas e máquinas de surfaçagem e nem a oferecer condições favorecidas para aquisição conjunta desses produtos. Transcreve-se abaixo o teor da cláusula 2.5 do TCD que previa tal remédio comportamental, in verbis:

2.5. As Compromissárias não poderão condicionar a aquisição de blocos e/ou lentes oftálmicas produzidos e/ou comercializados pelas empresas do Grupo Essior à aquisição de máquinas para surfaçagem de tecnologia tradicional produzidos pelas Compromissárias, ou vice-versa, nem oferecer condições favorecidas para aquisição conjunta de lentes e blocos oftálmicos produzidos pelas empresas do Grupo Essior e equipamentos de surfaçagem de tecnologia tradicional da fabricação das Compromissárias. 
67. Assim, no passado, o CADE impôs remédio comportamental voltado a impedir práticas a oferta em pacotes de produtos baseados em condições favorecidas nesse mesmo mercado. Essa obrigação prevista no TCD foi atestada cumprida por este Tribunal na 117ª Sessão Ordinária de Julgamento, nos termos do Despacho Presidência no 19 de 09.02.2018 (SEI no 0438702), o que só reforça a percepção da SG de que não haveria incentivos reais de condicionamento ou favorecimento na aquisição conjunta de produtos no nível de fornecimento de produtos oftálmicos para laboratórios.

68. Já em relação à prática de oferta de vouchers (com efeitos de rebate) na venda de máquinas de montagem para o varejo, verificou-se que tal prática foi adotada por um período limitado de tempo e com baixo impacto sobre o varejo, uma vez que o uso de tais equipamentos ainda é pouco difundido no mercado.

69. Ainda em relação aos mercados superiores da cadeia, a SG entendeu que não seria possível afirmar, de forma geral, que existem rebates com máquinas oftálmicas e substratos que gerem efeitos deletérios sobre concorrentes não vinculados ao programa Alliance da Essilor. Além disso, comparando os laboratórios Alliance e os não Alliance, identificou-se que esses últimos pagam, na média, valores inferiores àqueles que participam do programa da Essilor. Embora tal comparação tenha sido feita sem o controle de outras variáveis além do preço, tal resultado aponta no sentido de que não há diferenças significativas no fornecimento de substratos pela Essilor.

70. Sob uma perspectiva dinâmica, constatou-se ainda, a partir do exame da evolução de empregados nas fábricas de substratos oftálmicos da Essilor e de concorrentes (Zeiss e Hoya), bem como da evolução de importações no mercado entre 2006 e 2016, que a compra da Satisloh pela Essilor em 2009 não impediu a entrada de novos players no mercado brasileiro.

71. Nos níveis inferiores da cadeia (fornecimento de armações para óculos e varejo de produtos e serviços óticos), houve uma maior preocupação por parte da SG com possíveis imposições de poder de portfólio. Isso porque a Operação gera um player com participações relevantes e marcas conhecidas em uma série de produtos fornecidos ao varejo ótico, de sorte que o poder de portfólio poderia levar à venda conjunta desses produtos de lentes e armações de óculos de grau.

72. A partir dessa preocupação, a SG desenvolveu a análise de concorrência do abuso do poder de portfólio perante o varejo em três fases, examinando 
(i) a capacidade para adoção de práticas tendentes a fechamento de mercado; (ii) os incentivos para adoção de práticas tendentes ao fechamento de mercado e (iii) a probabilidade de geração de efeitos negativos como resultado da adoção de referidas práticas.

73. Ocorre que, nas três dimensões de análise, verificou-se que não haveria risco de fechamento de mercado em razão de particularidades muito claras do varejo de produtos e serviços óticos.

74. Na dimensão da capacidade, a própria SG verificou que "o varejo se demonstrou, na instrução, resistente à concentração do seu portfólio em um único fornecedor, principalmente em razão da necessidade de mais de um fornecedor de lentes oftálmicas". A partir das informações prestadas pelos agentes de mercado consultados, a SG concluiu que seria pouco provável a formação de bundlese a concessão de descontos em lentes e armações. Nesse sentido, destaca-se o trecho do parecer:

O desconhecimento da marca de lentes pelo consumidor, aliado à vontade das óticas de ofertarem um portfólio de lentes e óculos de sol e armações para óculos de grau amplo aos seus clientes (um portfólio amplo, principalmente, em questão de lentes ofertadas, afinal, como se viu, são as óticas as responsáveis por formar uma noção sobre o preço e a qualidade das lentes) torna pouco provável que bundles ou práticas com rebates envolvendo lentes e armações fechem, totalmente, os mercados envolvidos, com óticas se abstendo de aquisições de múltiplos fornecedores.

75. Além de não haver capacidade de fechamento de mercado, não foi possível colher da instrução indícios de que as Requerentes teriam incentivo econômico para adotar estratégias de oferta de descontos em armações/ óculos para alavancar vendas nos mercados de lentes, por exemplo. Tal constatação dependeria de dados sobre as margens das Requerentes na venda de cada um desses produtos, o que não foi possível obter na instrução do processo.

76. Por fim, quanto à probabilidade de essas práticas exclusionárias, caso fossem adotadas, gerarem efeitos concorrenciais negativos, a SG entendeu que esse juízo envolveria a ponderação entre:

De um lado, os benefícios gerados a curto prazo em razão da possibilidade de descontos da venda conjunta de produtos serem repassados 
a consumidores e, de outro lado, os prejuízos gerados a longo prazo em razão de incentivos para fechamento do mercado a concorrentes, o que pode acabar por prejudicar os consumidores. (SEI nº 0444536)

77. Ocorre que, no caso em apreço, conforme aponta a própria SG, "não foram encontradas evidências significativas de possibilidade de os efeitos negativos decorrentes da venda conjunta de produtos superarem os efeitos positivos dessa prática".

78. Desse modo, não prospera o argumento da Recorrente de que, por conta da concorrência limitada, no cenário da Operação ser implementada, a ZEISS e os demais agentes do mercado "não terão alternativas viáveis para contestar o poder dominante da entidade Essilor/Luxottica, possibilitando que as Requerentes aumentem preços e diminuam a qualidade de seus produtos". Na realidade, a instrução empreendida nos autos demonstra que, muito pelo contrário, a possibilidade de venda conjunta de produtos pode até mesmo aumentar o nível de concorrência no mercado varejista, possibilitando ofertas de produtos mais baratos ou de melhor qualidade, beneficiando o consumidor final - sem resultar em fechamento de mercado.

79. Assim, fica bastante claro que foi acertada a decisão da SG de aprovar sem restrições o ato de concentração, uma vez que (i) não foi diagnosticada capacidade de adoção de práticas exclusionárias perante o varejo, em função das próprias características de multisourcing do mercado de revenda; (ii) não foram comprovados incentivos econômicos para adoção de práticas tendentes ao fechamento de mercado e, mesmo que tais práticas eventualmente ocorressem, (iii) não há evidências de que seus efeitos seriam negativos sobre a concorrência. De fato, o exame cuidadoso de todas essas fases da análise de poder de portfólio confere bastante conforto ao juízo formulado pela SG.

80. Ademais, conforme já sustentei em meu voto relator no julgamento do AC no 08700.001097/2017-49 (Bayer Aktiengesselschaft e Monsanto Company), considero que as autoridades antitruste devem ter cautela ao considerar os chamados efeitos conglomerados como fundamento para a reprovação de atos de concentração ou mesmo a imposição de remédios.

81. No âmbito comparado, percebe-se que, tanto no direito antitruste norte-americano quanto no europeu, há um ceticismo cada vez maior quanto à intervenção estatal no âmbito de fusões conglomeradas. Nesse sentido, William Kolasky, ex-membro do Department of Justice nos EUA, chega a 
destacar que, depois de 15 anos com experiências dolorosas no controle de fusões conglomeradas, as agências norte-americanas têm concluído que o direito antitruste deve raramente, ou mesmo nunca, interferir em fusões conglomeradas:

After fifteen years of painful experience with these now long-abandoned theories, the U.S. antitrust agencies concluded that antitrust should rarely, if ever, interfere with any conglomerate merger. The U.S. agencies simply could not identify any conditions under which a conglomerate merger, unlike a horizontal or vertical merger, would likely give the merged firm the ability and incentive to raise price and restrict output. ${ }^{7}$

82. Na mesma linha, o Professor Robert Pitofsky, ex-presidente do Federal Trade Commission (FTC), afirma que houve um completo abandono da análise de fusões conglomeradas por parte da autoridade antitruste norte-americana, tendo em vista a dificuldade de se prever quando a combinação de portfólio implicaria um efetivo aumento dos incentivos de fechamento de mercado:

Theories once in vogue that a conglomerate merger should be challenged because the combined firm would be so large and powerful as to intimidate rivals, or so large and powerful as to extract special discounts from suppliers not available to smaller firms, have been eliminated from the guidelines and have not been the basis of challenge in over twenty years. ${ }^{8}$

83. No contexto europeu, principalmente em razão de decisões judiciais que cassaram decisões antitruste em controle de estruturas baseadas na análise de efeitos conglomerados, ${ }^{9}$ percebesse que houve um movimento por parte das próprias agências antitruste europeias no sentido de fixar parâmetros

7 KOLASKY, William J. Conglomerate Mergers and Range Effects: It's a Long Way from Chicago to Brussels. Address before the George Mason University Symposium, 2001.

8 PITOFSKY, Robert. Past, Present, and Future of Antitrust Enforcement at the Federal Trade Commission. University of Chicago Law Review, 2005, p. 218.

9 Nesse sentido, destaca-se principalmente a decisão judicial que determinou a anulação da decisão da Comissão Europeia no caso Tetra Laval/Sidel: "Since the effects of a conglomeratetype merger are generally considered to be neutral, or even benefical, for competition on the markets concerned..., the proof of anticompetitive conglomerate efects of such a merger calls for a precise examination, supported by convincing evidence, of the circumstances which allegedly produce those effects" (Tetra Laval, 2002, E.C.R II-4381, p. 155). 
que confiram uma maior objetividade a essa análise. Conforme pontuam Chen e Rey em estudo de 2015 sobre o tema: "The EC courts have imposed substantial requirements on the Commission to establish a merger violation on the basis of the theory of portfolio effects". ${ }^{10}$

84. No Brasil, estudo de 2017 dos professores Carolina Policarpo Garcia e Paulo Furquim de Azevedo intitulado "Should competition authorities care about conglomerate mergers?" examinou a questão a partir de uma análise da onda recente de aquisições de instituições de ensino superior por grandes grupos educacionais brasileiros.

85. A conclusão do estudo revela que, no cenário investigado, tanto fusões horizontais quanto fusões conglomeradas teriam permitido que os grupos educacionais fusionados se beneficiassem de economias de escala e de escopo, gerando melhor qualidade na prestação dos serviços. Contudo, diferente das fusões horizontais, apenas as fusões conglomeradas teriam possibilitado o repasse dos ganhos de eficiência aos consumidores. Nas palavras dos autores:

We provide robust evidence that multiunit educational groups benefit from scale and scope economies both in horizontal and conglomerate mergers, which translates to better quality indicators and evidence of quality perceived by students. Moreover price and quantity effects reveal that conglomerate mergers tend to pass on part of the efficiency gains to consumers (by means of higher quantity), differently from horizontal mergers that in average have a positive effect on prices but not on enrolment level. We also explored the dynamic effects, which showed that the magnitude of the effects has not been fully captured, since they appear to be still in progress over time. ${ }^{11}$

86. É claro que o estudo foca apenas em um cenário específico, que é o mercado de educação superior brasileiro. Além disso, verificaram-se efeitos heterógenos quanto ao repasse de ganhos de eficiência de acordo com o grupo educacional analisado, o que sugere a necessidade de aprofundamento caso a caso. De todo modo, o que fica claro é que, de um modo geral,

10 CHEN, Zhijun e REY, Patrick. A Theory of Conglomerate Mergers. Working Paper. 2015, p. 3. Disponível em: <www.cresse.info/uploadfiles/2016_pl2_pa1.pdf>.

11 GARCIA, Carolina Policarpo e AZEVEDO, Paulo Furquim de. Should competition authorities care about conglomerate mergers? World Economics Association (WEA) Conferences. Public Law and Economics, 2017, p. 29. 
as fusões conglomeradas geram preocupações menos acentuadas do que aquelas que se verificam no âmbito de fusões horizontais, o que corrobora a necessidade de cautela da autoridade antitruste na avaliação de possíveis remédios ou mesmo de cenários de reprovação.

\subsubsection{Ausência de comprovação de eficiências}

87. Por fim, a Recorrente também apresenta o argumento de que a aprovação da Operação teria sido determinada pela SG sem que fossem comprovados possíveis efeitos positivos resultantes do Ato de Concentração.

88. A Recorrente relata que a SG desenvolveu um juízo de ponderação entre os benefícios gerados a curto prazo em razão da possibilidade de descontos da venda conjunta de produtos serem repassados aos consumidores finais e, de outro lado, os prejuízos gerados a longo prazo em razão de incentivos para fechamento de mercado. Na opinião da Recorrente:

Os possíveis efeitos positivos decorrentes da Operação não foram comprovados. Na realidade, o Parecer contém exemplos genéricos de possíveis eficiências resultantes da Operação, tais como (i) redução dos custos de transação, (ii) incentivo a concorrência, (iii) concessão de descontos na venda conjunta de produtos, (iv) oferta de produtos mais baratos ou de melhor qualidade por concorrentes e, (v) em última instância, benefícios aos consumidores finais. Isto é, não há qualquer evidência de que a Operação efetivamente resulte em qualquer eficiência ao mercado consumidor no Brasil.

89. A Recorrente defende ainda que a necessidade de comprovação de eficiências em operações de natureza complexa vem sendo insistentemente enfatizada pela jurisprudência do CADE, de modo que, em Atos de Concentração como o ora analisado, o processo deveria ser instruído com demonstrações concretas dos efeitos líquidos positivos da Operação. Nesse sentido, a Recorrente cita diversos precedentes recentes deste conselho para fundamentar sua tese, como os casos Liquigás/Ultragaz, ArcelorMittal/ Votorantim e Ipiranga/Alessat.

90. Sobre esse ponto, esclarece-se que a jurisprudência recente do CADE tem de fato atribuído importância à comprovação de eficiências em atos de concentração complexos. Há que se entender, no entanto, que a 
avaliação de eficiências se revela imprescindível para aprovação de Atos de Concentração apenas quando, da análise concorrencial, conclui-se pela probabilidade do exercício de poder de mercado por parte das Requerentes em um cenário pós-fusão.

91. A análise de eficiências no controle de estruturas encontra amparo legal no $\S 6^{\circ}$ do art. 88 da Lei $\mathrm{n}^{\mathrm{o}} 12.529 / 11$, in verbis:

Art. 88. Serão submetidos ao Cade pelas partes envolvidas na operação os atos de concentração econômica em que, cumulativamente:

$\S 5^{\circ}$ Serão proibidos os atos de concentração que impliquem eliminação da concorrência em parte substancial de mercado relevante, que possam criar ou reforçar uma posição dominante ou que possam resultar na dominação de mercado relevante de bens ou serviços, ressalvado o disposto no $\S 6^{\circ}$ deste artigo.

$\S 6^{\circ}$ Os atos a que se refere o $\S^{\circ}$ deste artigo poderão ser autorizados, desde que sejam observados os limites estritamente necessários para atingir os seguintes objetivos:

I - cumulada ou alternativamente:

a) aumentar a produtividade ou a competitividade;

b) melhorar a qualidade de bens ou serviços; ou

c) propiciar a eficiência e o desenvolvimento tecnológico ou econômico; e

II - sejam repassados aos consumidores parte relevante dos benefícios decorrentes.

92. Conforme se depreende, a necessidade de comprovação, cumulada ou alternativa, dos objetivos previstos nos incisos I e II do $\S 6^{\circ}$ do art. 88 da Lei do CADE só se faz necessária quando o Ato de Concentração em exame preencher os requisitos do $\S 5^{\mathrm{o}}$ do mesmo dispositivo. Ou seja, a comprovação de eficiências só constitui condição sine qua non de aprovação de um Ato de Concentração quando se diagnostica que a Operação implica a eliminação da concorrência em parte substancial de mercado relevante, que ela pode criar ou reforçar uma posição dominante ou ainda que ela pode resultar na dominação de mercado relevante de bens ou serviços.

93. Corroborando esse entendimento, o Guia para Análise de Atos de Concentração Horizontal do CADE estabelece que a análise clássica de atos de concentração horizontais se desenvolve em cinco etapas, sendo que apenas 
a última delas corresponde à ponderação das eficiências econômicas inerentes ao AC. O Guia deixa claro que "os efeitos líquidos advindos do AC serão avaliados a partir da comparação entre os benefícios específicos resultantes da realização do AC e os potenciais prejuízos para o bem-estar dos consumidores advindos da eliminação de concorrência" ${ }^{12}$

94. Desse modo, deve-se ter em mente que o exame de eficiências é uma etapa posterior ao diagnóstico da autoridade antitruste que aponta para efeitos concorrenciais negativos da Operação. Daí porque a doutrina fala que a comprovação de eficiências tem uma verdadeira natureza de defesa (efficiency defense) que é invocada pelas Requerentes, com o intuito de desconstituir um vetor preliminar de reprovação da Operação. ${ }^{13}$

95. A questão tende a causar confusões entre os operadores do Direito Antitruste principalmente porque, no caso de fusões horizontais, há uma certa presunção de que a Operação, ao reduzir o número de players atuantes em dado mercado, é tendente a eliminar ou diminuir a concorrência. ${ }^{14}$ De fato, em operações dessa natureza, é possível pressupor que haverá um acréscimo de poder de mercado das empresas, de modo que a compro-

12 Conselho Administrativo de Defesa Econômica. Guia de Concentrações Horizontais. Julho de 2016.

13 Nesse sentido, Thomas Rosse e Ralph Winter mostram que houve uma evolução no direito norte-americano quanto à análise de eficiências em controle de estruturas. Os autores mostram que, sob uma perspectiva contemporânea "evidence of efficiencies now is a defense against a prima facie case that a merger will substantially lessen competition" (ROSS, Thomas W. e WINTER, Ralph A. The Efficiency Defense In Merger Law: Economic Foundations And Recent Canadian Developments. Antitrust Law Journal. 2005, p. 471). No mesmo sentido, Herbert Hovenkamp em artigo recente sobre o tema preceitua que "Merger analysis today takes efficiencies into account in two ways. First, it makes assumptions about efficiencies in determining where the line for prima facie illegality should be drawn. Second, it recognizes an efficiencies defense once prima facie illegality has been established, with the burden of proof on the defendant" (Herbert J. Hovenkamp. Appraising Merger Efficiencies. George Mason Law Review, 2017). Também na literatura nacional, corroborando a noção de efficiency defense, Ana Frazão pontua que: "Em casos de preocupações anticoncorrenciais graves, a operação entra em uma espécie de 'zona de perigo', de forma que apenas poderá ser aprovada caso haja a comprovação de eficiências que superem os efeitos negativos e sejam repassados aos consumidores parte relevante dos benefícios gerados. Por essas razões, fala-se na eficiência como uma defesa (efficiency defense) a ser invocada pelas partes. De fato, se a análise chegou à constatação de que o exercício de posição dominante é provável, tem-se aí uma presunção de ilicitude da operação, que apenas poderá ser afastada pela prova das eficiências que superem os efeitos negativos" (Ana Frazão. Direito concorrencial das estruturas. In: COELHO, Fábio Ulhoa. Tratado de Direito Comercial. São Paulo: Saraiva, 2015, p. 463).

14 A posição de que existe uma presunção de riscos concorrenciais que devem ser compensados pela comprovação de eficiências no controle de fusões horizontais pode ser contemplada em Massimo Motta. Competition policy: theory and practice. New York: Cambridge University Press, 2004, p. 234. 
vação de eficiências e o saldo de efeitos líquidos positivos podem ser relevantes para a aprovação do Ato de Concentração.

96. O mesmo não ocorre, porém, com fusões não horizontais, como é o caso da Operação em exame. Nessas situações, parece que a avaliação de eficiências depende sim da comprovação prévia dos possíveis e prováveis efeitos anticompetitivos da Operação por parte da autoridade antitruste. Ou seja, em regra, o exame de eficiências só acontece como uma etapa posterior à comprovação de que o exercício de poder de mercado no cenário pós-Operação é efetivamente capaz de gerar prejuízos à concorrência. Nessas hipóteses, como dito, o exame de eficiências se traduz muito mais como uma alegação de defesa (efficiency defense) das Requerentes, conforme preceitua a doutrina.

97. No caso em apreço, a análise empreendida pela SG não encontrou evidências de que os possíveis efeitos negativos decorrentes da venda conjunta de produtos seriam superiores aos benefícios da concessão de descontos aos consumidores finais. Ao contrário do que sustenta a Recorrente, essa conclusão não se baseou em meras suposições otimistas do mercado. Pelo contrário, esse entendimento da SG foi construído principalmente a partir da análise de manifestações de agentes de mercado atuantes no varejo de produtos e serviços óticos.

98. Conforme apurado na instrução do processo, os varejistas não enfrentam grandes obstáculos para realizar a troca de fornecedores de lentes e de óculos de sol e armações para óculos de grau. Na realidade, apurou-se que a maior parte dos varejistas hoje já trabalha com mais de um fornecedor para todos esses produtos, não havendo também dificuldades regulatórias ou contratuais para a troca, dado que não existem contratos de exclusividade e de fornecimento entre óticas e fornecedores. Essa conclusão, repisa-se, advém das informações prestadas por diversos players consultados ao longo do processo e não de uma mera suposição da SG.

99. Esse diagnóstico indica que, pelas suas próprias características, o varejo ótico demanda variedade, o que impossibilita a imposição de portfólios únicos das Requerentes. Por essa razão, não prospera a tese de que a presente Operação estaria sendo aprovada sem qualquer comprovação de eficiências. 


\subsection{Consistência da análise concorrencial}

100. Em síntese, a análise empreendida pela SG se mostrou consistente à luz das alegações trazidas pela Recorrente. Estas alegações se concentraram em três argumentos principais para questionar a decisão de aprovação sem restrições: (i) reforço da posição dominante em mercados verticalmente integrados; (ii) efeitos conglomerados capazes de criar incentivos à adoção de práticas exclusionárias ou discriminatórias; e (iii) ausência de comprovação de efeitos positivos advindos da Operação.

101. Com relação ao reforço da posição dominante em mercados verticalmente integrados, alegou-se que a Operação resultaria em um fechamento dos pontos de acesso da indústria brasileira para a fabricação e distribuição de produtos óticos. No entanto, viu-se que o perfil de atuação de Essilor e da Luxottica indica uma clara complementaridade entre seus produtos e serviços, o que, na análise concorrencial da SG, seria incapaz de gerar incentivos de fechamento de mercado. Além disso, a integração da Luxottica agrega baixo aumento da participação da Essilor nos mercados superiores da cadeia, enquanto a participação da Essilor no varejo agrega baixo aumento da participação da Luxottica no nível de revenda. Ressalta-se que as conclusões da SG e deste voto quanto a esse ponto se limitaram ao nexo de causalidade da operação - isto é, ao reforço de integração vertical proporcionado pela fusão aprovada. Desse modo, a análise que aponta para a aprovação sem restrições da Operação não abrangeu o exame dos eventuais efeitos anticompetitivos de integrações verticais prévias à Operação, principalmente no que diz respeito à verticalização nos mercados de fornecimento de substratos oftálmicos e de produção de lentes acabadas da Essilor, cujos laboratórios apresentavam participações de mercado elevadas em um cenário anterior à fusão com a Luxottica.

102. Quanto aos efeitos conglomerados, a SG fez análise detida e também afastou preocupações concorrenciais decorrentes da Operação. Enquanto a Recorrente alega que os concorrentes não terão alternativas para contestar o poder dominante da nova empresa Essilor/Luxottica, a instrução da SG demonstrou que a possibilidade de venda conjunta de produtos poderia até mesmo aumentar o nível de concorrência no mercado varejista, possibilitando ofertas de produtos mais baratos ou de melhor qualidade, beneficiando ao consumidor final - e sem resultar em fechamento de 
mercado. Além de compartilhar da análise empreendida pela SG no caso concreto, considero que as autoridades antitruste devem ter cautela ao considerar os chamados efeitos conglomerados como fundamento para a reprovação de atos de concentração ou mesmo a imposição de remédios. Essa consideração está em linha com precedentes do Tribunal de Justiça da União Europeia a respeito do controle judicial das decisões administrativas da Comissão Europeia, além de estudos acadêmicos recentes no mesmo sentido. ${ }^{15}$

103. Especificamente no que concerne aos supostos riscos de fechamento de mercado por imposição do poder de portfólio das Requerentes no varejo, principalmente por meio da adoção de bundles ou práticas com rebates envolvendo lentes e armações, a análise empreendida pela SG mostrou que não foi diagnosticada capacidade de adoção de práticas exclusionárias perante o varejo, em função das próprias características de multisourcing do mercado de revenda. Além disso, não foram comprovados incentivos econômicos de adoção de práticas tendentes ao fechamento de mercado nesse segmento e, mesmo que tais práticas eventualmente ocorressem, não foram verificadas evidências de que seus efeitos seriam negativos sobre a concorrência.

104. Sobre esse ponto, destaca-se que a SG identificou algumas práticas comerciais adotadas pelas Requerentes no cenário pré-Operação que poderiam gerar efeitos anticompetitivos associados à detenção de um portfólio amplo de marcas - tais como a concessão de descontos condicionados na compra de máquinas e substratos oftálmicos. Embora a instrução tenha relevado que a presente Operação não geraria incentivos de extensão dessas práticas para outros mercados, esclarece-se que a análise da SG não se debruçou sobre a legalidade de tais práticas. Na realidade, entendeu-se que a avaliação da licitude dessas condutas preexistentes deveria ser realizada, se fosse o caso, em procedimento específico, fugindo ao escopo de análise do Ato de Concentração.

15 Ver, por exemplo, a recente pesquisa publicada em 2015 pelos Professores Zhijun Chen (Universidade de Shanghai) e Patrick Rey (Universidade de Toulouse) sobre o tema: "The EC courts have imposed substantial requirements on the Commission to establish a merger violation on the basis of the theory of portfolio effects". Cf. CHEN, Zhijun e REY, Patrick. "A Theory of Conglomerate Mergers". Working Paper. 2015, p. 3. Disponível em: <www.cresse.info/uploadfiles/2016_pl2_ pa1.pdf $>$. Em sentido semelhante, Carolina Policarpo Garcia e Paulo Furquim de Azevedo. "Should competition authorities care about conglomerate mergers?". World Economics Association (WEA) Conferences. Public Law and Economics, 2017, p. 29. 
105. Em relação à alegação da Recorrente no sentido da ausência de comprovação de efeitos positivos, viu-se que a análise de eficiências é uma etapa final na instrução de Atos de Concentração que apontam para a existência de problemas concorrenciais. Isso porque, caso a Operação gere problemas concorrenciais, estes podem eventualmente ser compensados por eficiências. No entanto, a análise concorrencial feita pelo CADE não indicou um diagnóstico de problema concorrencial, pelo que se justifica a aprovação sem restrições a despeito de uma análise de eficiências. É o que se denomina de efeito líquido não negativo.

106. Em realidade, verificou-se que as alegações da Recorrente, ainda que legítimas do ponto de vista de um agente privado, foram feitas de forma genérica, sem qualquer elemento ou documento novo capaz de sustentar tais alegações e, nesse sentido, se contrapor às conclusões da Superintendência-Geral.

107. Abaixo segue um quadro consolidado da Operação, com os respectivos market-shares no mercado brasileiro:

\section{[ACESSO RESTRITO]}

108. Por fim, destaca-se que o cenário internacional corrobora a tese de aprovação sem restrições. Isso porque - diferentemente do alegado pela Recorrente, que sustenta haver particularidades no mercado brasileiro que justificam uma intervenção do CADE - os market-shares das Requerentes no Brasil não são superiores àqueles verificados na Europa. O quadro constante no Anexo I deste voto, de acesso restrito, ilustra tal comparação. Esclarece-se que a Recorrente não tem acesso a todas as informações de mercado, por conterem dados de acesso restrito, de modo que isto pode comprometer sua visão e argumentação com relação a esse ponto comparativo específico.

109. Aliás, destaca-se que a Operação foi notificada em 20 (vinte) jurisdições que possuem controle prévio, tendo sido aprovada sem restrições em todas as análises concluídas até o momento: mais precisamente, 15 (quinze) delas, ${ }^{16}$ considerando que 1 (uma) decisão foi por ausência

16 União Europeia, Estados Unidos, Austrália, Canadá, Chile, Colômbia, Índia, Israel, Japão, México, Marrocos, Nova Zelândia, Rússia, África do Sul e Coreia do Sul. 
de jurisdição ${ }^{17}$ e outras 4 (quatro) ainda estão pendentes de conclusão de análise. ${ }^{18}$

\title{
4. Dispositivo
}

110. Por todas as razões expostas acima, considera-se que a Recorrente não logrou apresentar, de forma suficiente para a reforma da decisão recorrida, motivos pelos quais o ato aprovado poderia implicar eliminação da concorrência em parte substancial de mercado relevante, reforço de posição dominante ou dominação de mercado relevante de bens e serviços.

111. Desse modo, já tendo conhecido do Recurso Voluntário nos termos do Despacho Decisório nº 2/2018/GAB5/CADE (SEI no 0456184), no mérito, nego provimento ao recurso, reestabelecendo a execução do ato de concentração aprovado pelo Despacho da Superintendência Geral do CADE (SG/Cade) no 230/2018 (SEI n⿳0 0444536), nos termos do art. 172, §1으, do RICade. Isso inclui o compromisso assumido pelas Requerentes de informar ao CADE todas as eventuais futuras aquisições nos mercados afetados pela Operação, ainda que não preencham os requisitos legais de notificação, para fins de monitoramento do setor, nos termos do §275 da Nota Técnica da SG (SEI 0445148).

Brasília, 27 de março de 2018

\section{PAULO BURNIER DA SILVEIRA}

Conselheiro-Relator

\begin{abstract}
Anexo I - Tabela de comparação de market-shares no Brasil e na Europa
\end{abstract}
[ACESSO RESTRITO]

Fonte: Requerentes (SEI nº 0457083)

\footnotetext{
Taiwan.

18 Brasil, China, Cingapura e Turquia.
} 